\title{
Towards Enriched Conceptions of Work Learning: Participation, Expansion, and Translation among Individuals With/In Activity
}

\author{
By Tara Fenwick, University of Alberta
}

\begin{abstract}
Despite the long recognition in HRD theory that learning is socially and materially situated in activity and relations, HRD literature indicates a continuing strong emphasis on individualistic theories representing learning as knowledge acquisition or individual development. It is argued here that understandings of work learning within HRD theory can be fruitfully enriched by more fully incorporating practice-based perspectives. Three contemporary theories that analyse learning as a relation of individuals with/in activity have been selected for discussion here: the participational perspective of situated cognition, the notion of expansion from cultural-historical activity theory, and the constructs of translation and mobilization presented by actor-network theory. While these are not particularly new to HRD, the contribution of this discussion is to bring together these theories, along with published empirical workplace research based on them, to highlight selected dynamics that may be useful tools for HRD theory development. One element in particular is read across the three theories: the dialectic of 'flying' and 'grounding', or lines of discontinuity and continuity characterising work learning. The argument is theory-driven, drawing from HRD literature of work learning and practicebased theories of social activity and knowledge production.
\end{abstract}

In the human resource development field, learning embedded in everyday work practice has been long recognized. Much HRD research has employed theories of informal and incidental learning, action learning, and conceptions of the 'learning organization' as a site of continuous collective knowledge-production. What these theories all have in common is emphasis on joint work activity as an important site for learning. This site exists alongside, but certainly not subordinate to, formal instruction such as training interventions. Practice-based theories also insist that learning cannot be considered solely an individual process. Learning is understood to emerge from relations and interactions of people with the social and material elements of particular contexts. Context is thus considered carefully in terms of its divisions of labour and power relations, environmental affordances, cultural disciplines, language, and so forth.

These arguments have also occupied researchers in the broader social sciences, particularly in new sociology, feminist studies, cultural studies, critical management/organization 
studies and adult education. Debate continues about the precise nature of the relations among people, objects and discourses, the nature of mutual reconfiguration that occurs in these interactions, and the nature and location of knowledge that is generated. New practice-based theories and models have emerged to explain these issues, drawing from evidence that is being produced through ethnographic studies of learning in various work organizations (Beckett, 2001; Belfiore, et al., 2004; Fenwick, 2002; Gherardi and Nicolini, 2000; Sawchuk, 2003).

It is argued here that understandings of work learning within HRD theory can be fruitfully enriched by more fully incorporating these practice-based theories. All focus on closely tracing the knowledge that is produced, reinforced or transformed by subjects with/in activity. That is, they focus on learning that occurs through both the dynamics of individuals acting in the cultural forces configuring them, and the relations of individuals with their social others and with the activities and objects flowing through these relations. Three practice-based perspectives that analyse learning as a relation of individuals with/in activity have been selected for discussion here. First is the participational perspective of situated cognition (Wenger, 1998). Second is the notion of expansion from cultural-historical activity theory (Engeström, 2001). Third are the constructs of translation and mobilization presented by actor-network theory (Latour, 2005). Some of these constructs are not new to HRD professionals and learning theories, notably the participational perspective with its corollary notion of community of practice.

The particular contribution of this article is to bring these three perspectives together, along with recently published findings of empirical research based on each theory, to illuminate threads that may be most useful to enrich further development of work learning theories for HRD. Because these three perspectives are each complex and internally contested, an extended dialogue among them is not possible within the confines of the present discussion. Instead, one work 
learning dynamic has been chosen to read against all three: a dialectic of 'flying' and 'grounding' in individuals' negotiation of learning with/in activity. 'Grounding' refers to lines of continuity in learning: processes of conserving knowledge, seeking roots and place, establishing identity and stabilizing innovation. 'Flying' refers to lines of discontinuity or flight: activities of innovation, ongoing improvisation, knowledge transformation, identity shifts, and what Beckett (2001) has called hot action. The flying/grounding trope represents a dynamic that has been discussed in different ways in organizational learning literature (Weick and Westley, 1996).

The first section of the article examines theories of learning in work that continue to be promoted in HRD literature to show where and why practice-based theories might be helpful. The second section outlines the three theoretical perspectives represented as participation, expansion, and translation/mobilization. The third section develops the trope of flying and grounding in work learning, illustrating the insight offered to this dynamic by the three theoretical perspectives. The final section returns to HRD theory to consider implications of the discussion for expanding conceptions of work learning as individuals with/in activity.

\section{Current HRD Theories of Learning in Work}

Theorists such as Watkins and Marsick (1993) helped push HRD to consider the entire organisation, its objects, people and structures, as continuous collective learning activity. However this important work seems to have been overwritten somewhat by theories returning to focus on the individual. A recent meta-review of work learning literature compared articles published 1999-2004 in 10 journals (drawn from fields of human resource development, organization/management studies, and adult education) (Fenwick \& Rubenson, 2005). HRD articles about learning (in Human Resource Development International and Human Resource 
Development Quarterly) found a continuing strong presence of two perspectives in particular: learning as individual knowledge acquisition, and learning as individual human development.

\section{Learning as individual acquisition or development}

In the acquisitive perspective, learning is characterized as an individual human process of consuming and storing new concepts and skills/behaviours, frequently in terms of translating learning to capabilities that add to organizational resources (Nafukho et al., 2004). Research has focused on how to 'harness' or draw out and use the individual's acquired knowledge. Preoccupations include transferring acquired knowledge to practice, measuring competency (reliable valid measures and competence definitions are identified as problematic), and narrowing the gap between training investment and results (Bates and Holten III, 2004; Enos et al., 2003; Wiethoff, 2004)

In the perspective of individual human development, the assumption is that the individual learns and then affects the group, but the purpose is more about developing individuals than producing skills and innovation for the organization (Jacobs and Washington, 2003). The general base is constructivist learning, e.g. through reflection. As well, respect for the individual's history is emphasized, with focus on the individual's meaning-making and helping individuals to continually learn. Research preoccupations include how to promote the individual's self-directed learning capability, and how to understand the relation of work to individual developmental processes (Clardy, 2000; Straka, 2000). The role of the collective is described in terms primarily that foster the individual's learning ability.

In the Human Resource Development Review recent publications have examined and promoted continuous learning that occurs in work activity. Rarely, however, is consideration given to the nuances of knowledge emergence in practice through considering the complex 
movements, constructions and choices of the individual with/in material activity and social interaction. For example, Maurer's (2002) integrative model of employee learning and development focuses on the individual's cognitive, affective and behavioral processes, with almost no attention paid to either social interface or context, including practice or activity. Another model of work-related learning (Doornbos, Bolhuis \& Simon, 2004) emphasizes the importance of 'non-educational' social interactions as a learning site and attends carefully to the influences of context on these interactions. However this model stops short of theorizing the actual knowledge-producing dynamics and their cultural-political influences that occur among the individuals in activity. Yang's (2004) model of 'holistic learning' builds on Nonaka and Takeuchi's notions of tacit and explicit knowledge, adding 'emancipatory' knowledge. These notions are premised on a fundamental assumption of learning as individual knowledge acquisition and transfer. While promising, the model does not break away from a fundamentally individualist and static orientation. Nor does its delineation of the foundation, manifestation and orientation 'layers' of knowledge account for the actual negotiations of individuals and objects in joint activity. These negotiations are enabled or constrained by particular conditions that generates a form of knowledge (or doesn't). The same issue emerges in Danielson's (2004) theory of socialization as a process of continuous learning. While finely detailed, this theory elides system dynamics with individuals' cultural learning. What is missed are the nuanced everyday motions and interactions through which activity is negotiated, social norms constructed and reinforced, and individual identities constituted as performances of socialization. And with the exception of Yang's model none of these theories account for power, which by now is taken to be fundamental in theorizing work learning.

\section{Limitations of individualistic work learning theories}


But what is wrong with models of work learning as individual acquisition of knowledge or as individual human development? Why should learning theories expand and enrich their analyses of the dynamics of activity? First, acquisition implies that learning is additive, and that knowledge is a pre-existing substance ingested by the learning individual. Acquisition does not often account for how people construct, individually and collectively, different meanings of their experiences. Nor does it dwell on how adults revisit and re-construct these meanings, resist or ignore certain meanings, or how they often experience transformation of identities and knowledge through collective action and reflection. A focus on the individual also disregards the role of sociocultural participation, the collective interplay of minds, bodies, tools and action in work learning. The acquisitive notion of knowledge has been refuted by critics given individuals' apparent inability to carry knowledge across space and time (Hager, 2004). Folk wisdom simply admits "use it or lose it": human experience suggests knowledge is embedded in everyday action, not in heads or even in bodies as dislocated skills. Studies of work communities also show that knowledge tends to be distributed among participants, rather than being concentrated within individuals (Cook \& Yanow, 1993). In fact, there is general consensus now that instead of considering what and how work knowledge is acquired, research ought to focus on what and how environments and forms of participation produce particular practices of activity and knowledge (Billett, 2004a,b).

Capabilities exist as chains of behavior that are holistic and embedded in collective activity (Chaiklin \& Lave, 1993). Learning to use a hammer effectively, for example, is influenced by the carpenter's value ascribed to the hammering task in relation to the overall project and the specific task difficulty. Hammer use is also affected by the network of activity, both material and social, of which the hammering is part. Cultural norms of hammering and tools shape the learner's hammer use, as do specific situational distractions and pressures. In fact, recent spatial concepts 
of work learning have shown how particular spatio-temporal architectures function as pedagogies that invoke particular work knowledge and behaviours (and subjectivities) (Edwards and Nicoll, 2004).

Humanistic conceptions of work learning as individual development draw in large part from models of reflective experiential learning popularized in particular by Kolb (1984). Individuals are encouraged to mentally reflect on their concrete experience to construct and transform their own unique knowledge. This conception is useful for attending to the individual's personal sensemaking in work learning. However there has been a tendency to overemphasize and under-theorize the role of reflection in certain renditions of informal/incidental learning, action learning, and organizational learning. Experience is often cast as a fixed thing, separated from knowledge-making processes. What becomes prominent are individual mental representations of events, static and distinct from the interdependent commotion of people together, in action with objects and language (Fenwick, 2003). Taken to extremes, this view separates mind and body, thinking from doing, and individual from collective. Meanwhile the notion of 'development' has been criticized as rooted in hierarchical and deficit-oriented assumptions: that workers need to move from less- to more-complete, as determined by the gaze of the educator or HR planner, in a progressive trajectory cast in chronological time (Fenwick, 2006).

Critics also have shown how conventional a-political approaches to workplace learning ignore the power relations that determine hierarchies in what learning is most valuable, what counts as skill, and what knowledge remains marginal or unnamed. Feminists have long called attention to gendered determinations of work knowledge that persist (Jackson, 1991; Probert, 1999). Traditional distinctions between men's and women's work knowledge reinforce a system of male dominance. Class hierarchies also obscure important work knowledge. Clerical workers 
for example, enact complex knowledge in relationship-building, conflict mediation, social organizing, creative problem-solving, knowledge translation and so on, much of which remains officially unrecognized and undercompensated (Gaskell, 1995). Such 'invisible' learning may be critical for effective work operations but because it is activity-based, working in the spaces between people and objects, conventional work learning conceptions fail to account for it. Finally, power relations in organisations configure arrangements of activity and social divisions that enable some kinds of learning for some people, and constrain many others (Jackson, 1991; Sawchuk, 2003).

The problem for HRD practice is that unless it is based on learning models that adequately theorize the actual individual/social dynamics articulated in everyday practices, it risks underestimating the complexity of these dynamics and thus either repressing or being subverted by them. That is, the progressive possibilities for both individual and social change remain vague unless these dynamics are more closely understood. For these reasons contemporary theories of learning in work tend to have shifted from individualism to social learning perspectives (Sawchuk, 2003), from acquisitional to practice-based conceptions (Hager, 2004), and from atomistic to comprehensive systemic analyses that also account for micro-interactions within activity (Engeström, 2001). In addition, power relations are increasingly analysed so that learning theories address politics of knowledge, production and social difference that shape everyday activity and the learning generated within it.

\section{Contemporary Perspectives on Learning and Knowledge in Work}

Recent scholarship in work learning tends to accept that the learning process is simultaneously both individual and collective, and occurs in various contexts: everyday action, 
planning, conversation, projects, problem-solving, instruction, reading, and online activity

(Sawchuk, et al. 2005; Wenger, 1998). Three perspectives have been selected for discussion here: situated cognition, cultural-historical activity theory, and actor-network theory. While very different in orientation and argument, these perspectives share concern for how learning emerges as individuals interact and negotiate three main elements of practice: contextual structures and culture; dynamics of activity at different levels of analysis (language, group activity, collective change); and movements of knowledge. All analyse learning as individuals with/in activity, and all have been employed explicitly to analyse learning in work contexts. Each is rooted in different, often contested, positions about the nature of knowledge, the nature of being, the relation of learner to object, and the nature of practice. Some try to totalize the debate. But their various contributions suggest fruitful openings for reconsidering processes through which learning in work adapts, expands and changes.

\section{Learning as participation in situated practices}

Lave and Wenger (1991) in their theory of situated cognition argue that individuals learn as they participate in situ: by interacting with a particular community (with its history, assumptions and cultural values, rules, and patterns of relationship), the tools at hand (including objects, technology, language), and the moment's activity (its purposes, norms, and practical challenges). While this notion can probably be rehearsed by most HRD professionals, its proliferation in the past decade has resulted in sufficient variance that it is worth revisiting both the original theory and the body of empirical research that has accumulated to explore its premises. For Lave and Wenger in their original publication, knowing and learning are defined as engaging in changing processes of human participation in a particular community of practice (CoP). A CoP is any group of individuals who work together for a period developing particular 
ways of doing and talking about things that their members learn through action. A central element in these experiences is movement. Knowledge moves, it is not a static body of concepts that is acquired, stored, represented and managed. Billett (2004b) shows that individuals actively influence one another's knowledge and norms through a process of 'co-participation'. Thus knowing is interminably inventive and entwined with doing. The putative objective is to become a full participant in the CoP, not to learn about the practice. Lave and Wenger's (1991) original discussion was explicitly political, locating everyday knowledge-generating activity in opposition to formally coded 'knowledge' dispensed through schooling. The community itself defines what constitutes legitimate knowledge and practice. Thus the community continually reproduces and even entrenches knowledge in which new participants become grounded: cultural norms of interaction, methods of practice, identities, and divisions of labour and power.

Some analysts retain clear distinctions between the autonomous individual and others in the community. Billett (2004a) for instance examines interaction between affordances/constraints of environments and agency/biography of individuals, developing a theory of 'relational interdependency' between individuals' intentional action and the workplace CoP. The individual affects the community knowledge by injecting new ideas, and the community affects the individual's behavior through teaching. Research has explored differences among individuals in expectations, preferences and ways of participating (Filstad, 2004) including women and younger workers. Individual differences are reportedly affected by the collective's structures and opportunities/barriers to learning. Those with a greater sense of control over their work are more likely to engage in learning, such as in more democratic work structures or professionals developing individual expertise (Livingstone, 2001). The impact of the CoP on individual learning is greatest in socialization (task mastery, role clarification, and social integration) and in 
defining or demanding particular competencies, as well as in the reward system and values placed on learning (Driver, 2002).

The question we are left with is, how does knowledge of both individuals and the group actually change in a community of practice? What lines of flight - of either innovation or resistance - are possible in a CoP intent on reinforcing and grounding its knowledge through individuals' participation? Some empirical research has sought to explain the adaptation and reconfiguration of practices to meet changing pressures, and identify ways to facilitate these dynamics. Bogenrieder and Nooteboom (2002) found that community learning is affected by both relational stability (trust), variety (new ideas, risk) and group structure (networks, competence). New learning is constrained by time pressure, deferral, and centralization within and across projects (Keegan and Turner, 2001). Several studies have shown problems with the CoP model, including its insufficient analysis of macro-politics and solidarities within the community expertise and specialized knowledge (especially how to develop it during rapid change); individual habitus and agency/structure dynamics; and innovation, which appears to occur more at interface of CoPS than within them (Reedy, 2003; Swan et al., 2002).

However some have shown that even when embedded in social structures, individuals retain a 'durable disposition' to act (Mutch, 2003), and workers organize their own learning regardless of management boundaries and innovation expectations (Poell and Van der Krogt, 2003). So clearly dynamics which we might term 'flying' do emerge, apparently alongside and even induced by the lines of regulation that conserve and 'ground' the community's traditions. However on the whole, this participative perspective does not grant sufficient attention to the individuals' interactions within the community: individual difference in perspective, disposition, position, social/cultural capital, and forms of participation is unaccounted for. Therefore despite 
the contributions of this theory to understanding knowledge embedded in activity, a fine-grained analysis of individuals' actual interactions within activity is still lacking.

\section{Learning as expansion of objects and ideas}

Cultural-historical activity theory tries to account for these interactions with an "expansive" view of learning, defined as change in the joint action of a particular activity system. This view helps show the importance of socio-cultural interactions of individual perspectives, system objects and practice histories in generating knowledge. First it is important to understand that actual and possible action in an activity system is shaped by its "object", the problem at which activity is directed. Learning occurs as a cycle of questioning something in this activity system, analysing its causes, modeling a new explanation or solution, implementing this model in the system, reflecting on it and consolidating it (Engeström, 1999, 2001). This is a non-linear process, not a problem-solving cycle. The process simultaneously involves the system's goals, mediating artifacts or tools, and perspectives of participants. In fact, much back-and-forth activity revolves around finding consensus about what exactly is the problem, and what can be tolerated as a solution or innovation within the politics of the system.

Thus Engeström (1999) shows how innovation and change are both rooted and reconstructed or changed in the socio-cultural and historical activity systems in which individuals participate. What is viewed as novel or useful depends on what problems are perceived as uppermost in a particular time and space, what knowledge is valued most there, and indeed what knowledge can even be perceived, named and understood by its participants. Therefore, the innovative learning process must be understood as an interplay of individuals' choice-making and design within social relations constituted by material interests, cultural histories, and conflicting discourses. From within his theory of expansive learning in cultural-historical-activity systems, 
Engeström (1999, p. 384) explains innovative learning as the "construction and resolution of successively evolving tensions or contradictions in a complex system that includes the object or objects, the mediating artifacts, and the perspectives of the participants." The object (system objective), in particular, is constructed by actors to make sense of, name and stabilise a focus for their activities. These objects have histories and trajectories. They can provoke desire and resistance, and can generate identity or new forms of sociality. The creative potential of activity is closely related to moment-to-moment interactions among actors: they try to grasp the object or problem, redefine it, and seek openings for new possibilities within myriad constraints.

Sawchuk's (2003) study of technology learning among workers used cultural-historical activity theory. He showed how people participate in a wide array of computer learning practices that are "integrated with everyday life and mediated by artifacts including computer hardware and software, organizational settings, oral devices, class habitus, trade unions, and working-class culture" (p. 21). Encounters among participants are analysed to reveal how their "patchwork" of learning opportunities unfolds in informal networks across overlapping systems of activity - at home, with buddies, in computer labs, on the job. It is here where Sawchuk finds an 'enormous surplus' of knowledge production capacity as well as emancipatory potential for working class people.

Wright (2002) also revealed cultural-historical activity theory in his study of everyday learning and innovation in hi-tech teams (software developers). He found that it was almost impossible to separate individual skills and knowledge from what emerged collectively in the group. People and ideas were always moving in and out of each other's offices, and this interaction tended to circulate around the development of a prototype, which served as the 'object' of the activity system and the center of all the interactions. Bits of talk were usually 
accompanied by quick crude sketches, using desktop objects to expand an idea, moving back to the internet to snatch bits of data and statistics to check viability, calling others in to expand the idea creatively or to check constraints and standards. Thus participation in collective action to define a problem and achieve an objective - with tools, language and action, individual and group - is interminably connected with skill transformation. Furthermore, this action alternates rapidly between creative, expansive activity and validating, critical activity, between what is present and what is not yet: between flying and grounding.

\section{Learning as 'translation' and mobilization}

The point is that knowledge is always flying, on the move. It cannot be contained in any one element or dimension of a system. At the same time, the system's activity and knowledge are grounded in its routines, tools and power relations. The interplay of improvisation within the system's constraints is the key site for knowledge transformation. This is as true for trades and manual work as it is for work activities that are explicitly knowledge-based, like innovation or high-tech problem-solving. The question is, how exactly does this interplay between flying and grounding work in everyday practice?

Gherardi and Nicolini (2000) studied how cement-laying workmen learn safety skills, using actor-network theory to examine how knowledge is 'translated' at every point as it moves through a system. For example, one workman would show another how to adapt a new safety procedure to make a task easier, or two together would adapt a particular tool to solve a problem, depending on who was watching, of course. At other points in the system, the crew foreman negotiated the language of the safety assessment report with the industrial inspector. Deadlines and weather conditions caused different safety knowledge to be performed and different standards of evaluation. The equipment itself, and the crew's culture, embedded or 'grounded' a history of 
use possibilities and constraints that influenced the safety skills performed by those who interacted with the equipment. No skill or knowledge had a recognizable existence outside its use within the community.

Actor-network theory (ANT) provided the analytic frame for Gherardi and Nicolini's research. ANT is now considered a family of theories rather than one unitary conception (Latour, 2005). It explains that any changes we might describe as learning -- new ideas, innovations, changes in behavior, transformation - emerge through networks of actors. Edwards and Nicoll (2004) are among those applying ANT to understand workplace learning and pedagogies. Actors are entities (both humans and non-humans) that have become mobilized by a particular network into acting out some kind of work to maintain the network's integrity. Each entity becomes an actor by translating another actor, mobilizing it to perform knowledge in a particular way, such as a worker translating a foreman into a disciplinarian through a particular set of behaviors. Each entity also belongs to other networks in which it is called to act differently, taking on different shapes and capacities. A written contract, for example, is a technology that embeds knowledge, both from networks that produced it and networks that have established its use possibilities and constraints. In any short-term employment arrangement the contract can be ignored, manipulated in various ways, or ascribed different forms of power. Thus, no agent or knowledge has an essential existence outside a given network: nothing is given in the order of things, but performs itself into existence. Recent branches of ANT theory (Law and Hassard, 1999) have developed diverse iterations of these processes.

Another empirical example is evident in Biddle's (2004) study of everyday learning at a fire-fighting school. He used ANT to examine micro-processes of translation as the group integrated new technologies and adapted to new regulations. Particular innovations were enabled 
through strategies people used to interest, enroll, and mobilise others to perform particular skills. Fire - its risk and unpredictable danger, and its ability to paralyze newcomers - was also central. Fire and the tools of fire-fighting (the mantra was "put the wet stuff on the red stuff') 'grounded' the community's interactions, shaping how people interacted with one another and the forms of knowledge that were possible. The fire-fighting culture that had developed over many years also grounded the knowledge transactions being negotiated. This was an aggressively masculine culture of humour, toughness and brotherhood that continually mediated many operational tensions (expensive errors, conflicts over process, resistance to technology) arising in changing practices, while creating new (gendered) tensions as women began to challenge the dominance of masculinized practices and images.

\section{Lines of Continuity and Discontinuity: Grounding and Flying}

These three different theoretical formulations should not require reconciliation, for they are preoccupied with different objects of analysis and ideologies. Across them, however, are suggested elements in work learning processes that provide useful analytic tools for HRD.

First, multiple dimensions involved in learning need to be acknowledged. For example, identity issues are very much integrated in how people see themselves as knowers, and perform knowledge. Language is key to how people recognize and represent knowledge, how they name and exchange it, and how they construct meaning together of their experience. Practices, the everyday cultural routines in which people participate, embed symbols, values, and goals that determine what counts as learning, what is useful knowledge, what is correct and what is an error. Power relations structure hierarchies of knowledge within a community, determines who gets to judge learning, who has access to knowledge and who can participate in knowledge creation. Power also positions the community and its collective knowledge in regard to other communities. 
Second, these perspectives shed light on different levels and forms of work learning. Situated theories that show learning as participation in communities of practice provide an anthropological view of an overall system. Actor-network theory provides a micro-level view of how knowledge is actually negotiated or 'translated' at each interaction, and the politics influencing who or what can be seen and mobilized at any moment. Cultural-historical activity theory tries to link micro-interactions in practice to a macro-level view of how learning transpires over time, examining the historical emergence of a system's knowledge and tools, its structures of labour division and roles, and its changing objectives.

Third, each perspective suggests that learning moves in different directions depending upon task demands and contextual structures. Tropes of 'flying' and 'grounding' were employed to help suggest the nature of these directions in work environments. These directions are not mutually exclusive or oppositional: instead, work learning moves in both directions at once, suspending both in tension.

'Flying' is intended to capture dynamics associated with knowledge change: innovation or transformation regardless of its tempo or contour. Not only does the workplace construction of what counts as knowledge continually shift, but also the changing technology and tools conjuring particular skills create uncertainty and demand improvisation. The new focus on talk and text in many jobs (Farrell, 2001) and the increasing distribution of people and information across time and space causes knowledge to float. ANT studies show how knowledge 'flies' among actors and objects as they become mobilized in nets of activity. Particularly in contexts of rapid change in tasks and tools, workers often experience learning as a sort of flying. A study interviewing over 100 self-employed people, all who had left organizational employment to set up their own business and faced very steep learning curves to do so, found that participants actually referred to 
learning 'on the fly' or 'flying by the seat of your pants' (Fenwick, 2002). That is, they felt that their learning was entirely rooted in fast-paced action, almost intuitive and beyond logic. The action felt fast because they felt pressured to make decisions or invent solutions or produce something on the spot, without learned routines and strategies.

The contrasting movement of 'grounding' is also apparent in recent research of work knowledge and skill. When people talk about 'getting grounded', they usually mean getting their cultural bearings: learning sufficient norms and expectations to participate fully in the community, establishing their location both socially and geographically, and building sufficient competency to feel a comfortable sense of control. Individuals and groups seek continuity and stability as much as contingency. Studies of CoPs related in the preceding section show how 'grounding' can lead to entrenchment of certain practices and hierarchies in communities. History is also grounding, and research rooted in cultural-historical activity theory features both individuals' biographies and organizational narratives (e.g. Sawchuk, 2003). And finally the objects and tools being used are grounded sites where historical networks of flying work knowledge have become 'blackboxed' in ANT terms, conserved and often taken for granted, but always open to possibilities of reconfiguration.

All three perspectives suggest that people's engagement with others in activity involves, among other things, oscillation between these two contradictory but complementary movements of flying and grounding. These two dynamics are suspended together as knowledge is produced and changed through people's everyday activity and interaction. What actually goes on in this suspension is suggested in Beckett's (2001) organizational studies. When conditions are changing so rapidly that knowledge required to achieve a particular objective is not available, people still press on. They draw as much as possible from their 'grounding', their collective repertoire of 
previously learned patterns and rules of operating, but they blend this with a 'flying' improvisation. This improvisation moves beyond known patterns, trying and risking, with intention but not certainty: what Beckett calls confident extrapolation. In this extrapolation people experiment bodily as they mentally rehearse alternate possibilities. Simultaneously they observe and adjust the effects of their actions in the moment through "feedforwarding". The entire process of learning on the fly with feet on the ground is one of acting while negotiating and renegotiating in actual changing conditions.

Another example of the flying/grounding suspension and oscillation in work learning processes is offered by the case of identity. Individuals' and groups' sense of their own knowledge in work, and the knowledge valued by the collective to which they see themselves belonging, form a critical element of their sense of identity (Christenson \& Cheney, 2005). Further, their participation in work practices is entwined with the identities they come to inhabit within a particular community (Wenger, 1998). Identity work itself involves learning, for people in work environments labour to discern subject positions available to them, how and what identities to perform, and how others perceive their identity (Chappell, Tennant, Solomon and Yates, 2003).

In naming these two distinct movements, the danger is implying a flying/grounding binary as if these movements are separate and opposed. On the contrary, the work learning scholarship cited throughout this discussion tends to stress the interactions and interconnections between different movements: between micro and macro levels of learning, between system structures and individual actions, between planned and emergent processes, and between continuity and discontinuity.

\section{Implications for Work Learning Theory in HRD}


The foregoing discussion has argued that theories of work learning as individual knowledge acquisition and as individual human development continue to have prominence in HRD journal publications, despite the availability of more systemic, multi-faceted and actionbased learning theories introduced to HRD over 15 years ago. Individualistic and acquisitive learning theories are argued here to be highly limited, usually a-political and a-contextual, lacking historical and sociological analysis of knowledge generation, ignoring cultural psychology and geography, and unable to account for the dynamic and often contradictory interactions of individuals with and in the turbulence of everyday activity. Towards expanded conceptions of work learning, three contemporary bodies of practice-based learning theory were discussed: participative perspectives of situated cognition, expansion perspectives of cultural-historical activity theory, and translation/mobilization perspectives of actor-network theories. One dynamic of flying/grounding was explored as a device to read across these three theories. Each suggests that a 'flying' movement of learning as innovation, improvisation, shapeshifting and hot action interacts continually with a 'grounding' movement of learning as seeking location, establishing identity and stabilizing knowledge. The lines of flight do not replace but cut across the lines of continuity in the nets comprising any activity system: both are always present whether enacted or not. Individuals and groups might oscillate between 'flying' sorts of interactions in improvised activity, tolerance for open-ended fluid knowledge and relaxed boundaries, and 'grounding' sorts of interactions in fixing roots, conserving traditional practices and consolidating identities.

For HRD, these theories point to specific multiple dimensions, forms and levels, and directions of work learning that can be useful in analysing practical problems and formulating solutions. For example, the construct of 'skill' is rooted in a conception of knowledge acquired by individuals then applied or transferred to work tasks and problems. When workers are observed 
not to perform these tasks satisfactorily, causal logic diagnoses skill deficit in the workers and prescribes training to improve or transform skills. However in real work environments, this logic and its underlying conception has proven faulty. Safety training, for example, does not necessarily reduce accidents because safety behaviours are influenced by a host of factors unrelated to workers' performance ability: continuities in cultures of masculinity (Abrahamsson, in press); affordances and barriers for particular practices embedded in work environments (Billett, 2004a); discontinuities in shortcuts and subversions of Fenwickity, conflicting expectations emphasizing, for example, faster production and form-filling (Belfiore et al., 2004); and shifting micropolitics enacted among workers, foremen and safety inspectors (Gherardi and Nicolini, 2000).

In many organizations, leaders perceive knowledge gaps between what existing workers can do and the skill transformations demanded by factors such as technological reshaping of operations, implementation of internationalized standards, and accelerated innovation in product and process to compete globally. A conventional response to understanding such gaps from an individualist acquisitive view of learning is to focus on the worker: the problem becomes recruiting or upskilling individuals to fill the gap. However from the perspective of the theories presented here, the problem is more complex. Knowledge or skill has as much to do with what is actually recognized and mobilized as it does with workers' performed and observed capability. Even if it were possible to continually retrain workers or dramatically accelerate training, these approaches overlook the fact that many with needed skills can't get hired to matching jobs, and many in existing jobs say they have little opportunity to exercise the knowledge they already have developed (Livingstone, 1999). In other words, to analyse the issue of skill transformation in rapidly changing work environments, we must examine the whole system of continuities cut across by discontinuities at play. These analyses help illuminate how 'skills' and knowledge are 
constituted in organisational nets of social/economic relations, how and why skill demands are perceived to be shifting in these contexts, how knowledge is actually generated and recognized by individuals and groups in different positions, and how skills are mobilized or enabled in different activities. In fact in work environments particularly of rapid change, as people are compelled to transform their practices and understand their knowledge as more mutable and fluid, they are 'flying' by adopting what Gee (2000) calls "shapeshifting": they are literally learning to perform different selves and knowledges in different environments. Yet at the same time people employ deliberate strategies to anchor their identities: 'branding' themselves as skill specialists in particular areas, and constructing their own boundaries to delineate a work 'home' or sense of place (Fenwick, in press).

Taken together the three theoretical perspectives discussed in this article raise further questions for HRD consideration and research to clarify specific dynamics in learning processes occurring in work contexts. First are questions about what balance is created in different work contexts between processes of creating new knowledge, adapting/refining existing knowledge (e.g. flying), and institutionalizing or stabilizing new knowledge (e.g. grounding). How do practices and objects emerge in these difference contexts, and how do they become reconfigured? What actions and identities are mobilized in these contexts? Second are questions related to the actual nature of the interplay between the structural (labour process), cultural, and individual dimensions in generating and enacting knowledge. To what extent is a given work context more closed or more open? What factors most affect the relative closure or openness of activity and therefore learning? Third are questions about the extent to which rapid change such as in workplace technology is actually opening new possibilities and changing knowledge demands as opposed to fragmenting individual craft knowledge and whole tasks. How do the contradictory 
movements of 'upskilling' and 'deskilling' through technology affect the activities and therefore the learning of individuals and communities in a particular work context? To what extent is the need for grounding supported while flying is encouraged? And who gets to fly?

Such questions suggested by contemporary theories of work learning reviewed in this article draw attention to continuing dilemmas while opening new sites for dialogue and inquiry. For HRD theorists and practicing professionals, these explorations focus on understanding work learning processes as practice-based: rooted in activity in particular contexts, and marked by multiple dimensions, different forms and levels, and different directions of learning. Particularly in new times of what Bauman (2000) has called 'molten capitalism', these directions point to a continual dialectic in work learning: between dynamics of and fundamental needs for flying and grounding, between seeking transience or lines of flight through creative improvisation 'on the fly' and seeking anchored permanence or lines of continuity through entrenchment, stabilization and identity.

\section{Acknowledgements}

The suggestions offered by four reviewers of an earlier draft of this article are gratefully acknowledged.

\section{References}

Abrahamsson, L. (in press). Exploring construction of gendered identities at work. In Billett, S., Fenwick, T., \& Somerville, M. (Eds.), Work, Learning and Subjectivity. New York: Springer.

Ardichvili, A. (2003). Constructing socially situated learning experiences in human resource development: An activity theory perspective. Human Resource Development International, $6(1), 5-20$.

Bates, R. \& Holton III, E.F. (2004). Linking workplace literacy skills and transfer system perceptions. Human Resource Development Quarterly, 15(2), 153-170.

Bauman, Z. (2000). Liquid modernity. Cambridge: Cambridge Polity Press.

Beckett, D. (2001). Hot action at work: understanding 'understanding' differently. In T. Fenwick (Ed.), Socio-Cultural Understandings of Workplace Learning (pp. 73-84). San Francisco: Jossey-Bass/Wiley.

Belfiore, M.E., Defoe, T.A., Folinsbee, S., Hunter, J., \& Jackson, N. S (2004). Reading work: Literacies in the new workplace. New Jersey: Lawrence Erlbaum Associates. 
Biddle, M. (2004). Organizational learning in a fire and emergency training centre: Examining knowledge creating activity. Unpublished doctoral dissertation, University of Alberta.

Billett S (2004a). Co-participation at work: Learning through work and throughout working lives. Studies in the Education of Adults, 36 (2), 190-205

Billett, S. (2004b). Workplace participatory practices: Conceptualising workplaces as learning environments. Journal of Workplace Learning, 16 (5/6), 312-325

Bogenrieder, I. \& Nooteboom, B. (2004). Learning groups: what types are there? A theoretical analysis and empirical study in a consultancy firm. Organization Studies, 25 (2), 287-299.

Chaiklin, S. \& Lave, J. (eds) (1993). Understanding practice: Perspectives in activity and Context. New York: Cambridge University Press.

Chappell, C., Tennant, M., Soloman, N. \& Yates, L. (2003). Reconstructing the lifelong learner: pedagogy and identity in individual, organisational and social change. London: Routledge.

Christenson, L. T. \& Cheney, G. (2005). Integrated organizational identities: Challenging the "bodily" pursuit. Paper presented to the $4{ }^{\text {th }}$ Critical Management Studies conference, July, University of Cambridge.

Clardy, A. (2000). Learning on their own: Vocationally oriented self-directed learning projects. Human Resource Development Quarterly 11(2), 105-125.

Cook, S. D. N., \& Yanow, D. (1993). Culture and organizational learning. Journal of Management Inquiry, 2 (4), 373-390.

Danielson, M.M. (2004). A theory of continuous socialization for organizational renewal. Human Resource Development Review, 3 (4), 354-384.

Doornbos, A.J., Bolhuis, S., \& Simons, P. R-J. (2004). Modeling work-related learning on the basis of intentionality and developmental relatedness: A noneducational perspective. Human Resource Development Review, 3 (3), 250-274.

Driver, M. (2002). Learning and leadership in organizations: Toward complementary communities of practice. Management Learning, 33 (1), 99-127.

Edwards, E. \& Nicoll, K. (2004). Mobilizing workplaces: actors, discipline and governmentality. Studies in Continuing Education, 26 (2), 159-173.

Engeström, Y. (1999), "Innovative learning in work teams". In Y. Engeström, R. Miettinen, \& RL Punamaki (eds), Perspectives on Activity Theory (pp. 377-406), Cambridge University Press, Cambridge, UK.

Engeström, Y. (2001). Expansive learning at work: Toward an activity theoretical reconceptualization. Journal of Education and Work 14 (1), 133-146.

Enos, M.D., Kehrhahn, M.T. \& Bell, A. (2003). Informal learning and the transfer of learning: How managers develop proficiency. Human Resource Development Quarterly, 14(4), 369387.

Farrell, L (2001). 'The 'new word order'- workplace education and the textual practice of economic globalisation', Pedagogy, Culture and Society, 9, 59-77.

Fenwick, T. (2002). Canadian women negotiating working knowledge in enterprise: Interpretive and critical readings of a national study. Canadian Journal for the Study of Adult Education, 16 (2). 1-29.

Fenwick, T. (2003). Learning through experience: Troubling assumptions and intersecting questions. Florida: Krieger.

Fenwick, T. \& Rubenson, K. (2005). Taking stock: A review of work-learning literature 1999-2004. Proceedings of the International Researching Work and Learning Conference. Sydney: University of Technology Sydney, 
Fenwick, T. (2006). The audacity of hope: Towards poorer pedagogies. Studies in the Education of Adults, 38 (1), 6-20.

Fenwick, T. (in press). Escaping/becoming subjects: Learning to work the boundaries in boundaryless work. In Billett, S., Fenwick, T., \& Somerville, M. (Eds.), Work, Learning and Subjectivity. New York: Springer.

Filstad, C. (2004). How newcomers use role models in organizational socialization. Journal of Workplace Learning, 16 (7/8), 396-500.

Gaskell, J. (1995). Making it work: Gender and vocational education. In J. Gaskell \& J. Willinsky (Eds.), Gender in/forms curriculum (pp. 59-76). New York: Teachers College Press.

Gee, J P (2000). New people in new worlds: networks, capitalism and school. In Cope, B. \& Kalantzis, M. (Eds.) Multiliteracies: Literacy learning and the design of social futures (pp.43-69). London, New York: Routledge.

Gherardi, S. \& Nicolini, D. (2000). To transfer is to transform: The circulation of safety knowledge. Organization 7 (2), 329-348.

Hager, P. (2004). Lifelong learning in the workplace? Challenges and issues. Journal of Workplace Learning, 16 (1/2), 22-33.

Jackson, N. (1991). Skills formation and gender relations: The politics of who knows what. Geelong: Deakin University Press.

Jacobs, R.L. \& Washington, C. (2003). Employee development and organizational performance: a review of literature and directions for future research. Human Resource Development International, 6(3), 343-354.

Keegan, A. \& Turner, J.R. (2001). Quantity versus quality in project-based learning practices. Management Learning, 32 (1),77-99.

Kolb, D. A. (1984). Experiential learning. Englewood Cliffs, NJ: Prentice-Hall.

Latour, B. (2005). Re-assembling the social - An introduction to actor network theory. London: Oxford University Press.

Lave, J., \& Wenger, E. (1991). Situated learning: Legitimate peripheral participation. New York: Cambridge Press.

Law, J. \& Hassard, J. (1999). Actor network theory and after. Oxford: Blackwell.

Livingstone, D. (1999). The education-jobs gap: Underemployment or economic democracy. Toronto: Garamond Press.

Livingstone, D.W. (2001). Worker control as the missing link: Relations between paid/unpaid work and work-related learning. Journal of Workplace Learning, 13 (7/8), 308-317.

Maurer, T.J. (2002). Employee learning and development orientation: Toward an integrative model of involvement in continuous learning. Human Resource Development Review, 1 (1), $9-44$.

Mutch, A. (2003). Communities of practice and habitus: A critique. Organization Studies, 24 (3), 383-395.

Mirchandani, K. \& Slade, B. (2005). "You just have to be respectable to talk to": Contingency, learning and definitions of skill in a call center. Conference Proceedings for The Canadian Society for the Study of Adult Education. London, ON: University of Western Ontario.

Nafukho, F.M., Hairston, N.R. \& Brooks, K. (2004). Human capital theory: Implications for human resource development. Human Resource Development International, 7 (4), 545 551.

Poell, R.F. \& Van der Krogt, F.J. (2003). Learning strategies of workers in the knowledgecreating company. Human Resources Development International, 6 (3)387-403. 
Probert, B. (1999). Gendered workers and gendered work: Implications for women's learning. In D. Boud \& J. Garrick (Eds.), Learning in work (pp. 98-116). London: Routledge.

Reedy, P. (2003). Together we stand? An investigation into the concept of solidarity in management education. Management Learning, 34 (1), 91-110.

Sawchuk, P. (2003). Adult learning, technology, and working class life. Cambridge: Cambridge University Press.

Sawchuk, P., Duarte, N. \& Elhammoumi, M. (eds.) (2005). Critical perspectives on activity: Explorations across education, work \& everyday life. Cambridge: Cambridge University Press.

Straka, G. A. (2000). Conditions promoting self-directed learning at the workplace. Human Resources Development International, 3 (2), 241-251.

Swan, J., Scarbrough, H. \& Robertson, M. (2002). The construction of 'communities of practice' in the management of innovation. Management Learning, 33 (4), 477-497.

Watkins, K. \& Marsick, V. (1993). Sculpting the learning organization. San Francisco: Jossey Bass.

Weick, K.E. \& Westley, F. (1996). Organizational learning: Affirming an oxymoron. In S. Clegg, C. Hardy \& W Nord, (Eds.), Handbook of organization studies (pp. 440-458). London: Sage.

Wiethoff, C. (2004). Motivation to learn and diversity training: Application of the theory of planned behavior. Human Resource Development Quarterly, 15(3), 263-278.

Wenger, E. 1998 Communities of practice: Learning, meaning and identity. Cambridge: Cambridge University Press.

Wright, K. (2003). Exploring the Learning Through Work Processes of Expert Workers. Unpublished doctoral dissertation. Edmonton, Alberta: University of Alberta.

Yang, B. (2003). Toward a holistic theory of knowledge and adult learning. Human Resource Development Review, 2 (2), 106-129. 